
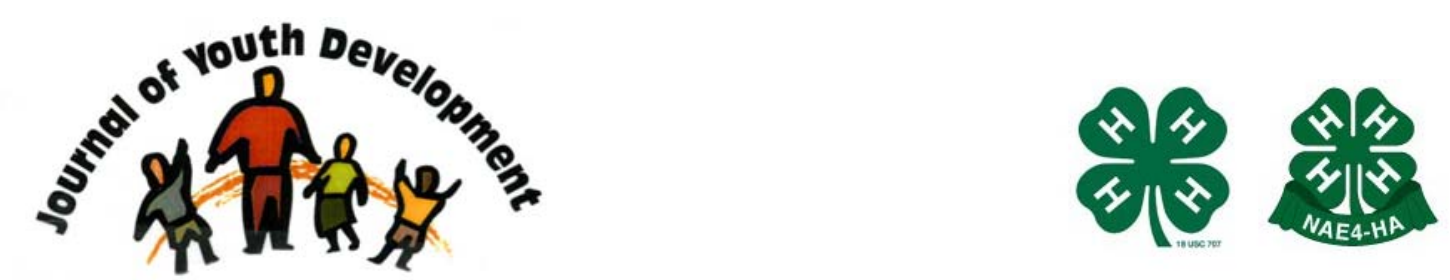

Bridging Research \& Practice

\title{
Mothers' Satisfaction with Youth Out-of-School-Time Programs
}

\author{
J uyoung J ang \\ Family Social Science Department \\ University of Minnesota \\ St. Paul, MN \\ jangx095@umn.edu \\ Jodi Dworkin \\ Family Social Science Department \\ University of Minnesota \\ St. Paul, MN
}




\title{
JOURNAL OF YOUTH DEVELOPMENT \\ bridging research and practice

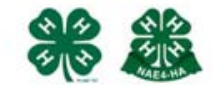

Volume 7, Number 4, Winter 2012

Article 120704FA002

\section{Mothers' Satisfaction with Youth Out-of-School-Time Programs}

\author{
Juyoung Jang and Jodi Dworkin \\ University of Minnesota
}

\begin{abstract}
The purpose of this study was to investigate the factors related to mothers' satisfaction with youth out-of-school-time (OST) programs. The relationship to demographic characteristics and the effects of mother's perception of youth OST program opportunities on mothers' satisfaction with OST programs are discussed in this paper. Ordered logistic regression revealed the positive effects of partner's working hours, mother's education, and mother's perception on mother satisfaction. Generalized ordered logit models further revealed that the effects of the variables and the effects of child sex, income, and race differed by the level of mother satisfaction. These findings have important implications for youth workers and policy makers.
\end{abstract}

\section{I ntroduction}

Research on youth suggests that participation in out-of-school-time (OST) programs have several positive effects on youth development. Youth who participate in OST programs are more likely to have better school achievement (Cooper, Valentine, Nye, \& Lindsay, 1999), prosocial attitudes (Zaff, Moore, Papillo, \& Williams, 2003), and less likely to dropout of school (Mahoney \& Cairns, 1997) than young people who do not participate in OST programs. Parents can influence youths' OST program participation by encouraging participation and providing support for program participation (Morrissey \& Werner-Wilson, 2005).

Previous research has focused on how familial demographic characteristics such as income and ethnicity affect youth OST program participation. Minority families and low-income families might have difficulties accessing attractive OST programs (Simpkins, Ripke, Huston, \& Eccles, 2005), and consequently, those youth might not be able to participate or continue their participation (Coulton \& Irwin, 2009; Weitzman, Mijanovich, Silver, \& Brazil, 2008). Although research has revealed an association between demographics and OST program participation, there is a lack of understanding regarding how demographics are related to parental 
satisfaction with OST programs. When parents are more satisfied with OST programs, youth participation increases. Thus, the purpose of this study was to investigate the factors related to mothers' satisfaction with OST programs.

\section{Literature Review}

Though youth OST program participation has been studied extensively, the parent perspective has rarely been explored. Previous studies about youth participation in OST programs have revealed that participation differs by income, race/ethnicity, parent's working status, and neighborhood (e.g., Duffet, Johnson, Farkas, Kung, \& Ott, 2004; Hofferth \& Sandberg, 2001; Simpkins et al., 2005).

Youth of low income families have been found to be less likely to participate in OST programs (Simpkins et al., 2005; Weitzman et al., 2008). Non-White parents were more likely to report low levels of parental satisfaction with out of school time opportunities than White parents (Weitzman et al., 2008). Brown and Evans (2002) examined the relationship between OST programs and ethnicity and found that participation rates and hours in programs were greatest for White youth compared to those of other ethnicities. Among minority youth, Hispanic youth were least likely to participate in OST programs and those who participated tended to spend less time in the programs (Brown \& Evans, 2002; Weitzman et al, 2008). Ethnic minority parents have also reported challenges in finding OST programs which were available, affordable, and high quality. Because family income level was generally associated with race and ethnicity, the patterns of OST program participation of minority youth have been found to be similar to those of youth in low income families (Duffet et al., 2004).

Neighborhood has also been found to affect youth's participation in OST programs (Coulton \& I rwin, 2009). Since youth living in neighborhoods with high crime rates can be exposed to illegal activities or violence and spend time with deviant peers, formal OST programs can protect youth from negative societal influences (Posner \& Vandell, 1994). However, those same neighborhood characteristics can deter youth from participating in OST programs (Borden, Perkins, Villarruel, \& Stone, 2005; Coulton \& Irwin, 2009). For instance, high risk neighborhoods might experience a lack of available OST programs for youth at risk for poor developmental outcomes (Eccles, Barber, Stone, \& Hunt, 2003). Parent's working status is also related to youth participation in OST programs. Children of single employed-parent or two fulltime employed-parent families were more likely to participate in OST programs than children of non-employed parents and of two-parents with only one working (Weitzman et al, 2008).

\section{Parental Satisfaction with OST Programs}

There is little study about parental satisfaction with youths' OST programs. The limited research that does exist has revealed that parental satisfaction is related to youths' level of participation. Parents whose children had limited participation in OST programs reported lower satisfaction than parents with children participating regularly in activities (Weitzman et al., 2008). Weitzman and colleagues (2008) argued that low parental satisfaction with OST programs was closely related to family resources. More specifically, low income families and parents with limited higher education were likely to report low levels of satisfaction. Parents of low income families tended to have difficulties finding OST programs which were high quality or affordable. In addition, parents reporting low satisfaction indicated that issues of convenience and availability were things they would like to change. 


\section{Research Questions}

The present study was designed to address the neglect of the parent perspective in previous literature, by recognizing parents as critical to youth OST program participation. Specifically, two research questions were explored:

a) Are mothers' perceptions of OST program opportunities related to demographic characteristics (child's age and gender, household income, mother's race, marital status, working hours, and education level, partner's working hours, and residential area)? and,

b) How are demographic characteristics and mothers' perception of OST program opportunities associated with mother satisfaction with OST programs?

\section{Procedure}

\section{Method}

The data for this study comes from phone interviews with a statewide sample of Minnesota households with children in $7^{\text {th }}$ through $12^{\text {th }}$ grade. Data were weighted to ensure the sample was representative of Minnesota households. The original study was conducted by Dale Blyth and Ann Lochner in 2008 (see Lochner, Allen, \& Blyth, 2009) and made possible with funding from the Minnesota Department of Education, McKnight Foundation, the Minnesota Department of Human Services, Youth Community Connections, and the University of Minnesota Extension Center for Youth Development. The study was designed to understand parent and youth perceptions of the supply and demand for community learning opportunities. In 2008, using random digit dialing, telephone interviews were conducted with 1,487 mothers and 808 youth (787 pairs) about OST programs. The lower sample size for youth was primarily the result of not having parental permission and the young person not being available when the interviewer called. The overall response rate was $56.4 \%$, calculated based on contacted eligible households. Missing data ranged from $0.13 \%$ to $3.0 \%$, resulting in 690 parent-youth pairs with complete data. Since our sample size is sufficiently large, listwise deletion does not cause a reduction in statistical power (Acock, 2005).

\section{Measures}

Mother satisfaction with out-of-school-time (OST) programs. The dependent variable was mother satisfaction with OST programs. Three questions were used to create categories of mother satisfaction with OST programs. First, "Thinking about how [child's name] spends (his/her) time when (he/she) is not in school, if you could choose, would you basically stick with things the way they are, or would you change the way [child's name] spends (his/her) time?" The response options were "basically stick with things" or "change things." Second, "How do you feel about the activity and program options you and [child's name] have to choose from?" Response options were "there are enough options," "there needs to be more options", or "there are just too many options to choose from." Third, "As a parent, how much of a struggle is it for you to make sure [child's name] has things to do when (he/she) is not in school?" Response options were: "something you have under control," "something you struggle with only occasionally," or "something you struggle with on a regular basis."

Based on their responses, mothers were divided into three groups: low satisfaction (0), middle satisfaction (1), or high satisfaction (2). Those who reported negative responses for all three questions (i.e., "change things" for the first question; "there needs to be more options" or "there are just too many options to choose from" for the second question; and "something you struggle with only occasionally" or "something you struggle with on a regular basis" for the third question) were categorized as the low satisfaction group (23.9\%). Those who reported mixed responses (i.e., "basically stick with things," "there needs to be more options," and "something 
you have under control") were coded as the middle satisfaction group (52.6\%). Those who reported all positive responses for the three questions ("basically stick with things," "there are enough options," and "something you have under control") were categorized as the high satisfaction group $(23.5 \%)$.

Mother's perception about out-of-school-time (OST) program opportunities. Mother's perception about OST program opportunities in their community included six individual items. Mothers were asked how hard they thought it was to find activities and programs in their communities with the following characteristics: (a) trustworthiness, (b) affordability, (c) convenient location, (d) interesting to child, (e) age appropriateness, and (f) high quality. The range of responses was from "very easy to find" (1) to "very hard to find" (4). Response options were reverse coded such that higher scores indicated more accessible programs.

Demographic characteristics. Mothers reported annual household income, current working hours, partners' working hours, residential area, and highest level of education (see Table 1).

Table 1

Descriptive Statistics (Note. Sample is weighted.)

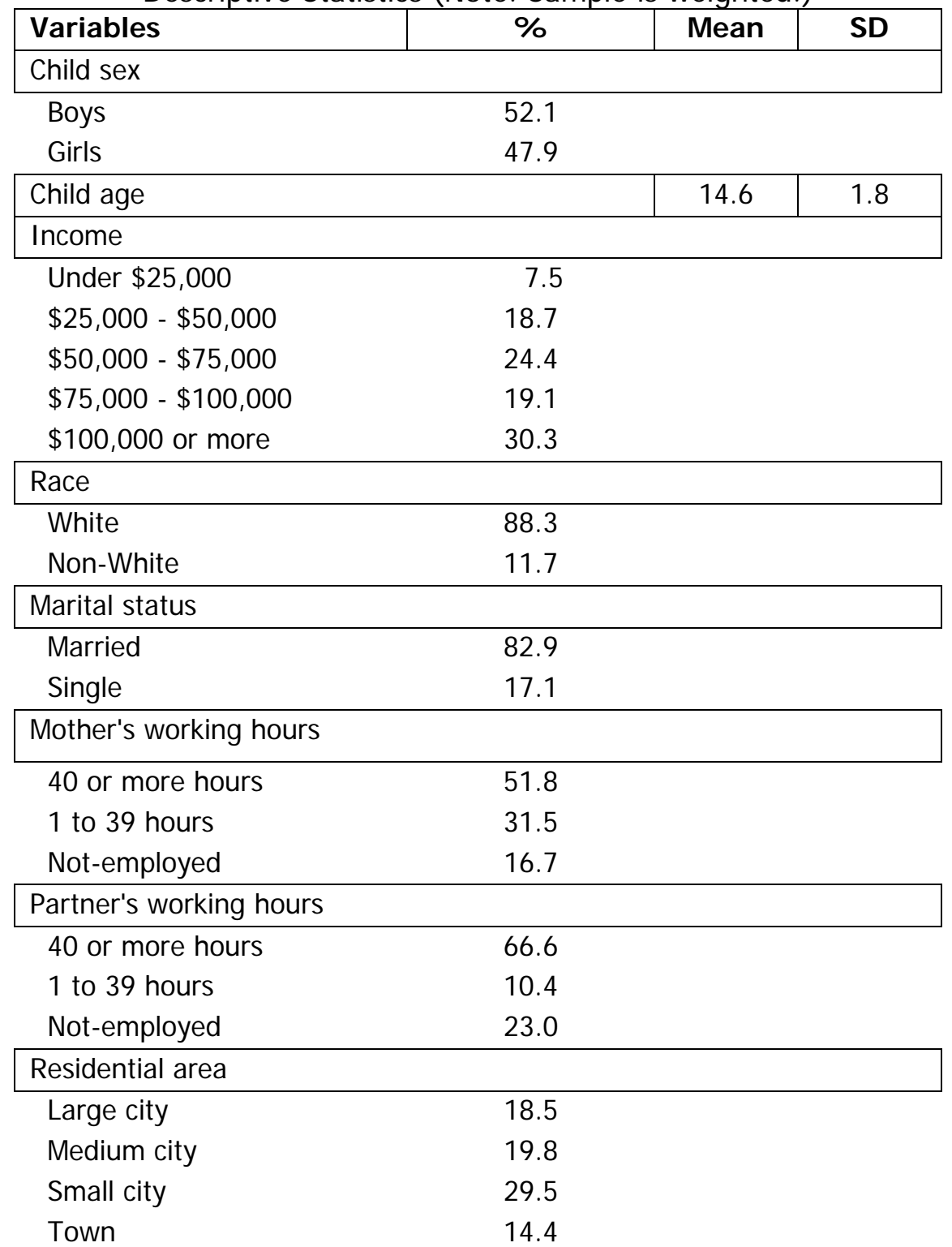




\begin{tabular}{|c|c|c|c|}
\hline Rural area & 17.7 & & \\
\hline Mother's education level & & & \\
\hline Less than high school & 2.2 & & \\
\hline High school graduate & 14.4 & & \\
\hline Some college & 21.5 & & \\
\hline Associate's/2-year degree & 15.1 & & \\
\hline Bachelor's/4-year degree & 29.9 & & \\
\hline Graduate school & 16.9 & & \\
\hline \multicolumn{4}{|l|}{ Mother's perception } \\
\hline Trustworthiness & & 1.8 & 0.9 \\
\hline Affordability & & 2.3 & 0.9 \\
\hline Convenient location & & 1.9 & 0.9 \\
\hline Interesting to child & & 2.0 & 0.9 \\
\hline Age appropriateness & & 1.9 & 1.0 \\
\hline High quality & & 2.1 & 0.9 \\
\hline
\end{tabular}

\section{Results}

To explore the first research question, Pearson's correlation tests, T-tests and ANOVA tests were computed. Correlation analyses revealed when a mother perceived it was easier to find out of school activities or programs which fulfilled one of the characteristics - trustworthiness, affordability, convenient location, interesting to child, age appropriateness, and high quality, it was also easier to find activities or programs which satisfied the other aspects.

T-tests revealed that mothers of girls perceived that it was easier to find OST activities or programs interesting to their child than mothers of boys $(t=2.01, p<.05)$. No other gender differences emerged. Mother's race, marital status, and residential area were all significantly related to the perception variables. White mothers perceived that it was easier to find OST programs that were trustworthy, affordable, convenient, age appropriate, and high quality than non-White mothers. Similarly, married mothers perceived that it was easier to find OST programs satisfying all six aspects than did single parents. Mothers living in large cities reported the most difficulty finding OST programs which were trustworthy, affordable, conveniently located, interesting to the child, appropriate for child's age, and of high quality. Mothers living in rural areas reported the most difficulty finding OST programs in a convenient location.

To examine the second research question, both ordered logistic regression and generalized ordered logit models (Fu, 1999; Williams, 2006) were performed. In this study, we had three categories of the dependent variable, low, middle, and high satisfaction. Ordered logistic regression was conducted to reveal the factors increasing parental satisfaction with OST programs, then, generalized ordered logit models were performed to explore varied effects of the independent variables on each level of parental satisfaction. Six ordered logistic regressions and six generalized ordered logit models were performed, each model including one of the six perceptions about OST program opportunities. The sample was weighted based on region population; unless otherwise specified all analyses were conducted using the weighted sample.

Ordered logistic regressions revealed the positive effects of partner's working hours, mother's education level, and mother's perception about OST program opportunities on mother satisfaction with OST programs. Mothers whose partner worked 1 to 39 hours were more likely 
to be satisfied with OST programs than those with a non-employed partner $(p<.05)$. In addition, mothers with higher education levels were more likely to report higher OST program satisfaction $(p<.05)$. The six measures of mother's perceptions about OST program opportunities were positively related to mother satisfaction with OST programs. Mothers who perceived that it was easy to find OST programs in their community which fulfilled each of the six categories were more likely to report higher satisfaction with OST programs than those who perceived that it was hard to find them $(p<.001)$.

Next, we performed generalized ordered logit models to examine the influences of independent variables across levels of parental satisfaction with OST programs (see Table 2). Using generalized ordered logit models, we obtained two sets of estimates: (a) the odds of having at least middle satisfaction (middle or high satisfaction) relative to having low satisfaction, and (b) the odds of having high satisfaction relative to having low or middle satisfaction. The odds ratio over 1 indicates that higher values on the independent variable make it more likely that mothers will have higher satisfaction than the current satisfaction level. 
Table 2

Generalized Ordered Logit Models for Mother Satisfaction using Mother's Perception

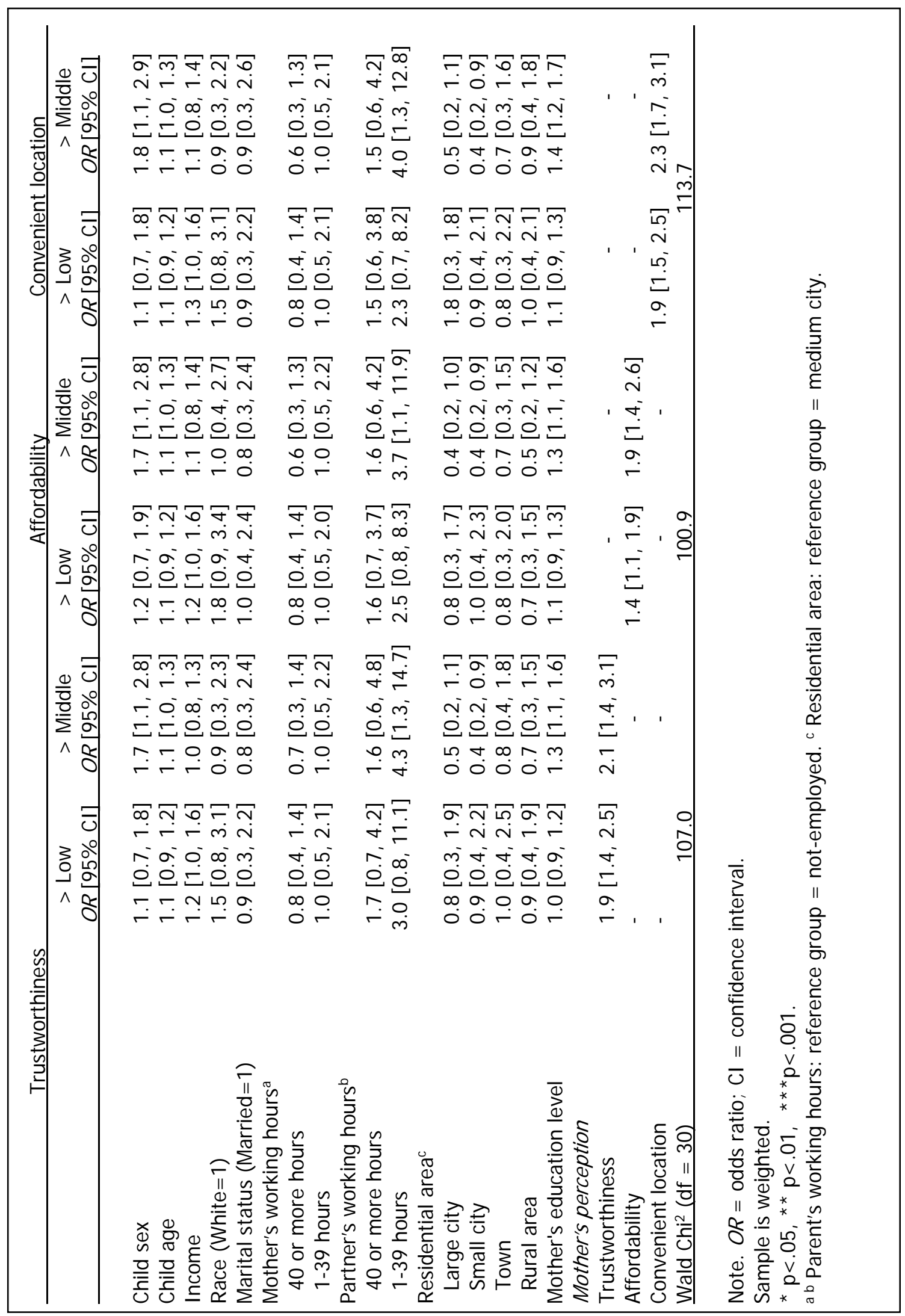


It was revealed that the independent variables influencing the odds of having at least middle satisfaction (middle or high satisfaction) relative to the odds of having low satisfaction were different from those affecting the odds of having high satisfaction relative to having low or middle satisfaction. Here we focus on the patterns of influence that were revealed.

Table 3

Generalized Ordered Logit Models for Mother Satisfaction using Mother's Perception (Con't)

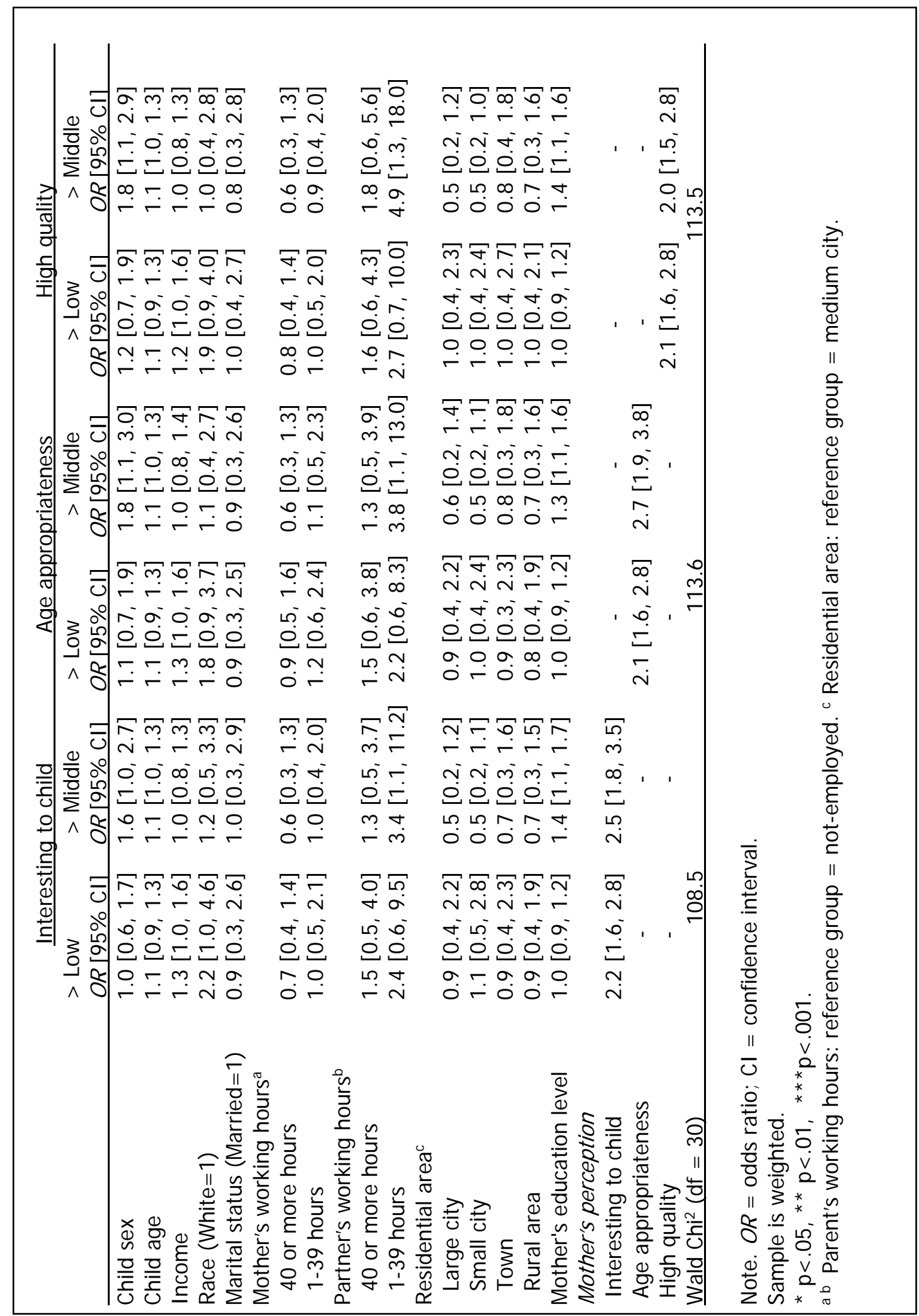


Next, we performed generalized ordered logit models to examine the influences of independent variables across levels of parental satisfaction with OST programs (see Table 2). Using generalized ordered logit models, we obtained two sets of estimates: (a) the odds of having at least middle satisfaction (middle or high satisfaction) relative to having low satisfaction, and (b) the odds of having high satisfaction relative to having low or middle satisfaction. The odds ratio over 1 indicates that higher values on the independent variable make it more likely that mothers will have higher satisfaction than the current satisfaction level.

Across the six models, mother's perception about OST program opportunities was the most significant factor influencing mothers to have at least middle satisfaction OST programs. Mothers who perceived that it was easy to find OST programs which were with trustworthy, affordable, conveniently located, interesting to the child, age appropriate, and high quality were more likely to have middle or high satisfaction compared to mothers perceiving it was not easy to find those programs. In addition, having higher income was associated with having at least middle satisfaction. When considering the variable interesting to the child, White mothers were more likely to have at least middle satisfaction compared to non-White mothers.

Additional demographic differences emerged when exploring the odds of having high parental satisfaction with OST programs. Mothers of girls were more likely to have high satisfaction relative to low or middle satisfaction than mothers of boys. In addition, mothers whose partner was working 1 to 39 hours a week were more likely to have high satisfaction compared to mothers whose partner was unemployed and those mothers who did not have a partner. Mothers having higher education were also more likely to have high satisfaction relative to low or middle satisfaction. For the models of mother's perception about trustworthiness, affordability, convenient location, and high quality, residential area was also associated with having high satisfaction. Compared to mothers living in a medium sized city, mothers living in a large city were more likely to have high satisfaction in the affordability model and those living in a small city were more likely to have high satisfaction in the trustworthiness, affordability, convenient location, and high quality models.

\section{Discussion}

Because parental influences are critical to youth OST participation and youths' OST program participation has a significant impact on their development, it is important to improve our understanding of OST programs from the perspective of parents. Although considering the parent perspective is essential, it is typically overlooked in OST research. In the present study, we addressed this gap.

First, this study revealed significant differences in parents' perceptions of OST program opportunities based on demographic factors. Low income mothers and ethnic minority mothers reported that it was more challenging to find activities that met their needs and desires. This in turn impacted their overall satisfaction with OST programs.

Second, partner's working hours, mother's education level, and mother's perception about OST program opportunities influenced mother satisfaction with OST programs. However, when we examined the effects of demographic characteristics and mother's perception on each satisfaction level, a more detailed picture emerged. Income and race played significant roles for switching from low satisfaction to middle satisfaction, which means that low-income, minority parents might have difficulties attaining at least middle satisfaction. On the other hand, to have high satisfaction, child sex, partner's working hours, mother's education, and 
residential area were critical. Mother's perception about OST program opportunities were related to increasing parental satisfaction with OST programs.

\section{I mplications}

The results of this study have important implications for youth workers. Youth workers often report challenges with attempting to improve the quality of OST programs and with developing programs to meet various needs of diverse populations (Mahoney, Parente, \& Zigler, 2009). Our study revealed that ethnic minority mothers and mothers with low SES experienced a lack of affordable and high quality OST programs. Further, minority and low SES mothers had lower satisfaction with OST programs than White and high SES mothers, even after accounting for their perception of OST opportunities. This may explain the low participation rate of youth in those families. However, it also suggests that youth workers need to work to understand the complex contexts beyond parents' SES that make an OST program highly satisfying for families. For example, residential area was important for mothers to have high satisfaction with OST programs. Residential area may simply be a proxy for community contexts such as neighborhood safety or school setting which would undoubtedly impact youth OST activities. Thus, to deliver effective OST programs that meet families' demands, youth workers need to understand and consider the community context of programs.

Findings also reveal a demand for more high quality programs in large cities and programs that are available to low income and ethnically diverse youth. The good news is that when parents reported it was easy to find a program that met one of their needs (e.g., interesting to child) they also reported it was easy to find a program that met their others needs (e.g., trustworthy and affordable).

These data provide essential information to expand the scope of the field of OST to include the parent perspective and more specifically to explore parent satisfaction with OST programs. A strength of this study is the use of matched parent and youth data, providing a more holistic view of out of school time. However, these data represent mothers from one Midwestern state and are cross sectional. Although our demographics (beyond gender) are representative of the state, they do not allow us to explore demographic differences in more detail. Future research should use longitudinal data to better capture the influence of parental satisfaction with OST opportunities on youth outcomes.

\section{References}

Acock, A. (2005). Working with missing values. Journal of Marriage and Family, 67, 1012-1028.

Borden, L.M., Perkins, D.F., Villarruel, F.A., \& Stone, M.R. (2005). To participate or not to participate: That is the question. New Directions for Youth Development, 105, 33-49.

Brown, R., \& Evans, W.P. (2002). Extracurricular activity and ethnicity: Creating greater school connection among diverse student population. Urban Education, 37(1), 41-58.

Cooper, H., Valentine, J.C., Nye, B., \& Lindsay, J.J . (1999). Relationships between five afterschool activities and academic achievement. Journal of Educational Psychology, 91 (2), 369378.

Coulton, C., \& Irwin, M. (2009). Parental and community level correlates of participation in outof-school activities among children living in low income neighborhoods. Children and Youth Services Review, 31, 300-308. 
Duffet, A., Johnson, J., Farkas, S., Kung, S., \& Ott, A. (2004). All work and no play? Listening to what kids and parents really want from out-of-school time. New York: Public Agenda.

Eccles, J.S., Barber, B.L., Stone, M., \& Hunt, J. (2003). Extracurricular activities and adolescent development. Journal of Social Issues, 59 (4), 865-889.

Fu, V.K. (1999). Estimating generalized ordered logit models. Stata Technical Bulletin, 8 (44), 27-30.

Hofferth, S.L., \& Sandberg, J.F. (2001). How American children spend their time. Journal of Marriage and Family, 63 (2), 295-308.

Lochner, A., Allen, G., \& Blyth, D. (2009). Exploring the supply and demand for community learning opportunities in Minnesota. Center for Youth Development, University of Minnesota Extension. Retrieved from http://www1.extension.umn.edu/youth/docs/Exploring-the-supplyand-demand-whole.pdf

Mahoney, J.L., \& Cairns, R.B. (1997). Do extracurricular activities protect against early school dropout? Developmental Psychology, 32, 241-253.

Mahoney, J.L., Parente, M.E., \& Zigler, E.F. (2009). Afterschool programs in America: Origins, growth, popularity, and politics. Journal of Youth Development, 4 (3), Article 090403FA002.

Morrissey, K.M., \& Werner-Wilson, R.J . (2005). The relationship between out-of-school activities and positive youth development: An investigation of the influences of communities and family. Adolescence, 40 (157), 67-85.

Posner, J.K., \& Vandell, D.L. (1994). Low-income children's after-school care: Are there beneficial effects of afterschool programs? Child Development, 65, 440-456.

Simpkins, S.D., Ripke, M., Huston, A.C., \& Eccles, J.S. (2005). Predicting participation and outcomes in out-of-school activities: Similarities and differences across social ecologies. New Directions for Youth Development, 105, 51-69.

Weitzman, B.C., Mijanovich, T., Silver, D., \& Brazil, C. (2008). If you build it, will they come? Estimating unmet demand for after-school programs in America's distressed cities. Youth Society, 40 (1), 3-34.

Williams, R. (2006). Generalized ordered logit/partial proportional odds models for ordinal dependent variables. Stata Journal, $6(1), 58-82$.

Zaff, J.F., Moore, K.A., Papillo, A.R., \& Williams, S. (2003). Implications of extracurricular activity participation during adolescence on positive outcome. Journal of Adolescent Research, $18(6), 599-630$.

(c) Copyright of J ournal of Youth Development $\sim$ Bridging Research and Practice. Content may not be copied or emailed to multiple sites or posted to a listserv without copyright holder's express written permission. Contact Editor at: patricia.dawson@oregonstate.edu for details. However, users may print, download or email articles for individual use.

ISSN 2325-4009 (Print); ISSN 2325-4017 (Online) 